\title{
Radiative consequences of low-temperature infrared refractive indices for supercooled water clouds
}

\author{
P. M. Rowe ${ }^{1}$, S. Neshyba ${ }^{2}$, and V. P. Walden ${ }^{3}$ \\ ${ }^{1}$ Department of Geography, University of Idaho, Moscow, ID 83844, USA \\ ${ }^{2}$ Department of Chemistry, University of Puget Sound, Tacoma, WA 98416, USA \\ ${ }^{3}$ Department of Civil and Environmental Engineering, Washington State University, \\ Pullman, WA 99164, USA
}

Correspondence to: P. M. Rowe (prowe@ harbornet.com)

Received: 26 April 2013 - Published in Atmos. Chem. Phys. Discuss.: 12 July 2013

Revised: 21 October 2013 - Accepted: 1 November 2013 - Published: 9 December 2013

\begin{abstract}
Simulations of cloud radiative properties for climate modeling and remote sensing rely on accurate knowledge of the complex refractive index (CRI) of water. Although conventional algorithms employ a temperatureindependent assumption (TIA), recent infrared measurements of supercooled water have demonstrated that the CRI becomes increasingly ice-like at lower temperatures. Here, we assess biases that result from ignoring this temperature dependence. We show that TIA-based cloud retrievals introduce spurious ice into pure, supercooled clouds, or underestimate cloud optical thickness and droplet size. TIAbased downwelling radiative fluxes are lower than those for the temperature-dependent CRI by as much as $1.7 \mathrm{Wm}^{-2}$ (in cold regions), while top-of-atmosphere fluxes are higher by as much as $3.4 \mathrm{~W} \mathrm{~m}^{-2}$ (in warm regions). Proper accounting of the temperature dependence of the CRI, therefore, leads to significantly greater local greenhouse warming due to supercooled clouds than previously predicted. The current experimental uncertainty in the CRI at low temperatures must be reduced to account for supercooled clouds properly in both climate models and cloud-property retrievals.
\end{abstract}

\section{Introduction}

Clouds represent an important source of uncertainty in radiative flux, and therefore climate (Randall et al., 2007). Supercooled water clouds occur globally (e.g., Intrieri, 2002; Verlinde et al., 2007; Hogan et al., 2003; Hu et al., 2010; Zhang et al., 2010; Rosenfeld and Woodsley, 2000). Recent work has found that midlevel supercooled-liquid topped stratiform clouds make up $33.6 \%$ of midlevel clouds (Zhang et al., 2010). In the Arctic, ubiquitous supercooled liquid cloud is a significant driver of radiative flux (Cesana et al., 2012).

Radiative properties of supercooled clouds depend on microphysical properties (particle size and shape), as well as complex refractive index (CRI) spectra, over the full range of supercooled temperatures from freezing to the homogeneous freezing point of $235 \mathrm{~K}$ (Koop et al., 2000).

Figure $1 \mathrm{a}$ and $\mathrm{b}$ show that the infrared CRI of thermodynamically stable water (henceforth "water") is different from that of ice in key regions (Hale and Querry, 1973; Downing and Williams, 1975; Bertie and Lan, 1996; Warren and Brandt, 2008; Toon et al., 1994). For water, a prominent absorption peak appears at $600 \mathrm{~cm}^{-1}$ in the imaginary part of the CRI; in ice, a similar peak appears at $\sim 800 \mathrm{~cm}^{-1}$. This shift plays a key role in phase discrimination using infrared remote sensing. While the CRI of ice varies significantly with temperature, for water a temperature-independent assumption (TIA) is conventional, despite that most measurements were made at $\sim 300 \mathrm{~K}$ prior to 2005 .

Recent measurements of the CRI of supercooled water (Zasetsky et al., 2005; Wagner et al., 2005) are shown in Fig. 1c and d. The CRI of supercooled water is distinctly temperature dependent and is intermediate between liquid and ice. Zasetsky et al. (2004) attribute this behavior to lowdensity domains in supercooled water. They find evidence that the frequency of low-density domains increases from $300 \mathrm{~K}$ down to $240 \mathrm{~K}$. (Thus low-density domains may also explain the differences between the $273 \mathrm{~K}$ and the $300 \mathrm{~K}$ 

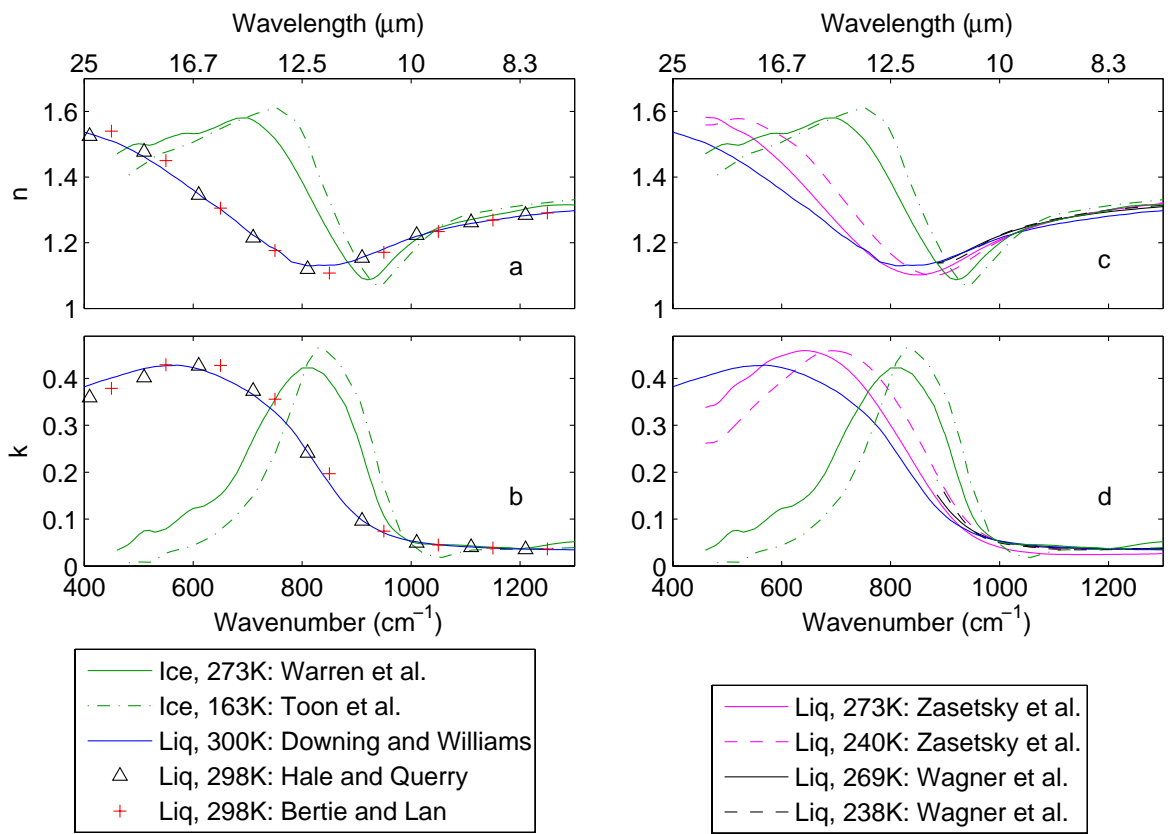

Fig. 1. Measurements of the complex refractive index (CRI) of ice and liquid water. Top panels show the real parts of the CRI ( $n$ : a and c), while bottom panels show the imaginary parts $(k: \mathbf{b}$ and $\mathbf{d})$. The left panels show the CRI of liquid water for temperatures of $298 \mathrm{~K}$ and above (made prior to 1996) while the right panels also include liquid water CRI at temperatures of $273 \mathrm{~K}$ and below (made in 2005).

CRI.) In light of this temperature dependence, it is important to assess the effect of the TIA on remote sensing retrievals and climate modeling.

In this paper, we compare simulated fluxes from supercooled liquid water clouds using the CRI of Downing and Williams (1975), based on measurements made at $300 \mathrm{~K}$, to simulated fluxes using a temperature-dependent CRI based on relatively recent measurements of Zasetsky et al. (2005) and Wagner et al. (2005) at temperatures of $273 \mathrm{~K}$ to $240 \mathrm{~K}$. In addition, we estimate errors in cloud-property retrievals from downwelling infrared radiance spectra for the TIA. Simulations are performed for single-layer liquid clouds, for a variety of atmospheric and cloud conditions and for both downwelling radiance/flux at the surface and upwelling radiance/flux at the top of atmosphere (TOA). In Sect. 2, we discuss the creation of a temperature-dependent CRI for supercooled liquid water, a hybrid that uses the best measurements of both Zasetsky et al. (2005) and Wagner et al. (2005). Section 3 gives the methods, including simulating radiances and fluxes and determining the spectral regions to use for the analysis. Section 4 discusses sources of error in the flux calculations. In Sect. 5, we present and discuss flux differences between simulations using the CRI of Downing and Williams (1975) and using the temperature-dependent CRI in two infrared spectral regions where clouds have a large signal and where the temperature dependence of the CRI appears to be well known: 460 to $640 \mathrm{~cm}^{-1}$ and 740 to $990 \mathrm{~cm}^{-1}$. Errors in cloud-property retrievals due to the TIA are also presented. Section 6 presents conclusions.

\section{A new CRI for supercooled water}

The measurements of Zasetsky et al. (2005) extend from 460 to $6000 \mathrm{~cm}^{-1}$ while those of Wagner et al. (2005) extend from 800 to $6000 \mathrm{~cm}^{-1}$. From 800 to $1000 \mathrm{~cm}^{-1}$ the imaginary parts of the CRI ( $k$ spectra) are typically within about $7 \%$ of each other. At wave numbers below $800 \mathrm{~cm}^{-1}$, near the peak in $k$, errors in Zasetsky et al. (2005) are expected to be $\sim 1.5 \%$, while from 1000 to $1300 \mathrm{~cm}^{-1}$, where $k$ is small, errors are large, rendering the refractive indices unusable. These large errors explain the poor agreement from 1000 to $1300 \mathrm{~cm}^{-1}$ between the $273 \mathrm{~K}$ indices of Zasetsky et al. (2005) and other indices (Fig. 1d; note that the solid magenta line is well below the other curves). By contrast, the method of Wagner et al. (2005) resulted in smaller errors in regions where $k$ is small. However, from 1000 to $1300 \mathrm{~cm}^{-1}$, even the uncertainties in the $k$ spectra of Wagner et al. (2005) are likely to be larger than the temperature dependence.

Based on these considerations, a new temperaturedependent set of refractive indices at temperatures of 240 , 253 and $263 \mathrm{~K}$ was created. From 460 to $800 \mathrm{~cm}^{-1}$, the new refractive indices are identical to the measurements of Zasetsky et al. (2005). From 800 to $1000 \mathrm{~cm}^{-1}$ they are intermediate between those of Zasetsky et al. (2005) and Wagner et al. (2005), changing linearly from the value measured by Zasetsky et al. (2005) at $800 \mathrm{~cm}^{-1}$ to the value measured by Wagner et al. (2005) at $1000 \mathrm{~cm}^{-1}$. From 1000 to $1400 \mathrm{~cm}^{-1}$, the measurements of Wagner 
et al. (2005) are used. Because the measurements of Wagner et al. (2005) were made at different temperatures (238, 252,258 , and $269 \mathrm{~K}$ ), they were first interpolated to the temperatures of Zasetsky et al. (2005).

\section{Methods}

\subsection{Simulations of radiance and spectral flux}

Radiances and spectral fluxes for supercooled liquid clouds were simulated as follows (more detail is given in the Supplement). Single-scattering parameters were created from the CRI using Mie theory. Atmospheric profiles were created for tropical, midlatitude summer, Arctic summer, midlatitude winter, and Arctic winter and inputted to a line-by-line radiative transfer model (LBLRTM; Clough et al., 2005) to get gaseous optical depths. Finally, downwelling and upwelling radiances and spectral fluxes were calculated using a program for discrete-ordinate-method radiative transfer in scattering and emitting layered media (DISORT; Stamnes et al., 1988), for each atmospheric profile (e.g., set of gaseous optical depths and temperature profile) and for a variety of liquid cloud effective radii and liquid water paths (LWPs).

Simulations were performed both for the TIA and for the temperature-dependent CRI. For the TIA, the singlescattering parameters for the CRI measurements of Downing and Williams (1975) for $300 \mathrm{~K}$ were used regardless of cloud temperature. For simulations using the temperaturedependent CRI, the single-scattering parameters used depended on cloud temperature; single-scattering parameters for the CRI at temperatures above and below cloud temperature were linearly interpolated to the cloud temperature.

\subsection{Choice of wave numbers}

The infrared spectral regions at which supercooled clouds have the greatest radiative effect depend on geographic location as well as the direction of flux (upward or downward). In order to select spectral regions that are sensitive to clouds and where the temperature dependence of the CRI is known, we focus on two extreme atmospheres - cold/dry and warm/wet (Arctic winter and tropical atmospheres; see Supplement) and examine downwelling infrared spectral fluxes as they would be measured by an upward-looking instrument at the surface, and upwelling infrared spectral fluxes as they would be measured by a downward-looking instrument at the top of the atmosphere.

Simulated clear-sky upwelling and downwelling flux spectra for the extreme atmospheres are compared to simulated cloudy-sky spectra, for single-layer liquid clouds with LWPs of $8 \mathrm{~g} \mathrm{~m}^{-2}$ and an effective radius $\left(r_{\mathrm{e}}\right)$ of $10 \mu \mathrm{m}$, placed at heights such that the cloud temperature is $240 \mathrm{~K} ; 240 \mathrm{~K}$ was chosen to explore the extreme low of CRI measurements. These comparisons are used to determine the spectral regions where the effect of supercooled water clouds dominates.
Figure 2a shows simulated upwelling spectral fluxes. From about 460 to $600 \mathrm{~cm}^{-1}$ (the "dirty window") and 800 to $1250 \mathrm{~cm}^{-1}$ (the "atmospheric window"), gaseous absorption is weak enough to permit some of the surface flux to be transmitted to the TOA. The effect of a tropical cloud (compare red solid curve to pink dashed curve) is considerable because the cloud $(240 \mathrm{~K})$ is much colder than the surface $(300 \mathrm{~K})$. By contrast, for Arctic winter clouds, there is little difference in temperature between cloud $(240 \mathrm{~K})$ and surface $(238 \mathrm{~K}$; a temperature inversion is present), so the cloud has little effect (compare solid blue curve to dashed light blue curve). Thus, for upwelling flux, the greatest sensitivity to supercooled cloud content occurs in warm locations where the temperature contrast between the surface and cloud is largest, in the window regions.

Figure $2 \mathrm{~b}$ shows simulated downwelling spectral fluxes. The clear-sky Arctic winter spectral flux is low in the window regions due to weak trace gas emission. The tropical clear-sky spectrum is more "filled in" than that of the Arctic winter, due to emission from water vapor in the warm, humid atmosphere. The dirty window is completely filled in, and thus there is no increase in downwelling flux for the cloudy tropical case. For both atmospheres, clouds cause an increase in downwelling radiance in the atmospheric window, but the increase is considerably greater in the Arctic winter. Thus for downwelling flux, the greatest sensitivity to supercooled cloud content occurs in cold, dry atmospheres, in the window regions.

Because clouds have little effect between 640 and $760 \mathrm{~cm}^{-1}$ and 1250 and $2000 \mathrm{~cm}^{-1}$ (due to strong absorption and emission by water vapor and $\mathrm{CO}_{2}$ ), and between 990 and $1050 \mathrm{~cm}^{-1}$ (due to $\mathrm{O}_{3}$ ), we exclude these regions from the spectral flux calculations used to determine flux differences for the TIA. From 1050 to $1250 \mathrm{~cm}^{-1}$ relative uncertainties in the CRI are large and the temperature dependence of the CRI is not well characterized (see Supplement), so we exclude this spectral region from the flux calculations. However, this region is important for clouds, and higher accuracy CRI measurements from 235 to $273 \mathrm{~K}$ are thus crucial for a complete understanding of the infrared radiative transfer of supercooled liquid clouds. The wave-number regions used in this study are, therefore, from 460 to $640 \mathrm{~cm}^{-1}$ and 760 to $990 \mathrm{~cm}^{-1}$. For cloud-property retrievals, 13 wave numbers in microwindows between strong gaseous emission lines are selected from these spectral regions: 465.2, 496.1, 531.3, 558.4, 765.8, 789.5, 809.0, 833.2, 860.2, 898.2, 929.6, 959.9, and $985.0 \mathrm{~cm}^{-1}$.

\subsection{Flux differences}

To determine biases in fluxes due to the TIA, spectral fluxes (in $\mathrm{W}\left(\mathrm{m}^{2} \mathrm{~cm}^{-1}\right)^{-1}$ ) were integrated over 460 to $640 \mathrm{~cm}^{-1}$ and 760 to $990 \mathrm{~cm}^{-1}$ and summed to get a flux (in $\mathrm{Wm}^{-2}$ ). The flux determined using the temperature-dependent CRI 

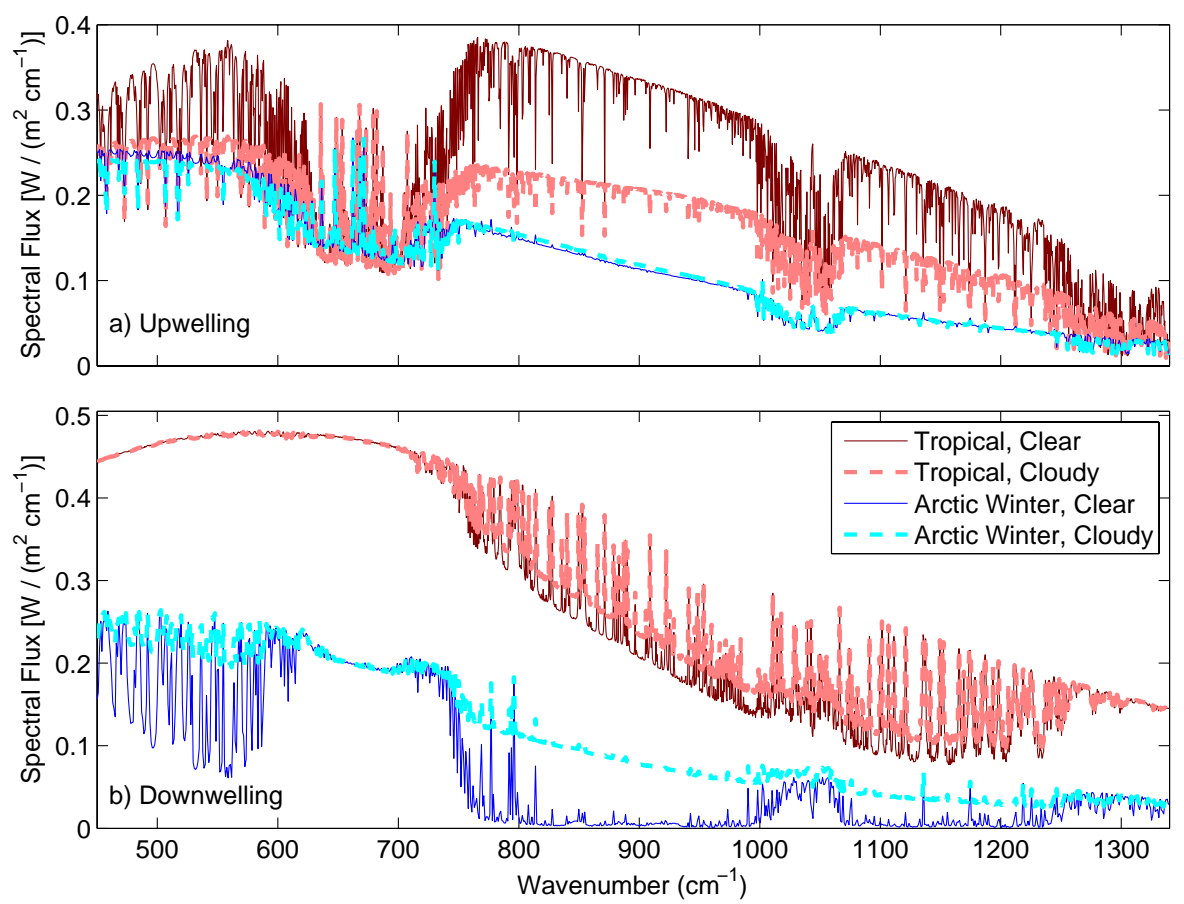

Fig. 2. Spectral fluxes from clear and cloudy skies for a warm/wet extreme model atmosphere (tropical) and a cold/dry extreme model atmosphere (Arctic winter). (a) Flux upwelling to the top of atmosphere and (b) flux downwelling to the surface. Plots are on a 1 wavenumber spacing. The model cloud is a single-layer liquid cloud with effective radius of $10 \mu \mathrm{m}$, and cloud liquid water path of $8 \mathrm{gm}^{-2}$, at a temperature of $240 \mathrm{~K}$, created using a conventional complex refractive index based on measurements made at $300 \mathrm{~K}$.

was then subtracted from the flux for the TIA to give the flux difference.

\subsection{Cloud-property retrievals}

Cloud properties can be retrieved from measured downwelling infrared spectra through inverse methods (e.g., Rodgers, 2000), or computationally slower but simpler forward methods. For our purposes, only a small number of retrievals are performed, so a forward method is used.

The forward method used here relies on creation of an extensive look-up table of simulated radiances in the $13 \mathrm{mi}-$ crowindows given in Sect. 3.2. Properties that will not be retrieved are held constant in creating each look-up table; since these vary from measurement to measurement, a separate look-up table is required for each measured spectrum from which cloud properties will be retrieved. Each cloud property that will be retrieved (i.e., ice effective radius and ice fraction or liquid effective radius and liquid water path) is varied over a range of physically reasonable possibilities. Thus the table is made up of sets of 13 radiances: one set for each unique set of cloud properties. Once the look-up table is created, the retrieval is performed by finding the set of simulated radiances from the table that minimizes the rootmean-square difference between simulated and measured radiances. The cloud properties corresponding to the chosen simulation are then the retrieved values.
For the purpose of determining errors in cloud-property retrievals due to the TIA, we create model radiances to serve as the "measurements." Although these are modeled, we will refer to them as measurements by analogy with standard cloud retrievals and to avoid confusion between them and the simulated radiances making up the look-up tables. For all measurements, the cloud temperature is set to $240 \mathrm{~K}$ and the CRI measured at $240 \mathrm{~K}$ is used. Simulations making up the lookup table also all have cloud temperatures fixed at $240 \mathrm{~K}$, but rely on the CRI measured at $300 \mathrm{~K}$. Thus retrieved cloud properties will have errors due to use of the incorrect CRI in the retrieval.

Two groups of measurements and look-up tables are created. The first group is designed to explore errors in retrieved cloud ice fraction due to the TIA. For this group, the total water path and liquid $r_{\mathrm{e}}$ will not be retrieved and thus are fixed in the look-up tables to the same values as for the measurements. Instead, ice fraction and ice $r_{\mathrm{e}}$, which will be retrieved, are varied in creating the look-up table (ice $r_{\mathrm{e}}$ is varied from 1 to $100 \mu \mathrm{m}$, and ice fraction is varied from 0 to 1 ; ice and liquid are modeled as external mixtures, included in the same volume). The measurements are all for liquid-only clouds. Since the measurements contain no ice, a retrieved ice fraction greater than 0 constitutes error in the retrieval due to the TIA. 
The second group of measurements and look-up tables is designed to explore errors in retrieved liquid water path and liquid $r_{\mathrm{e}}$ due to the TIA. For this set, all measurements as well as look-up-table simulations are for liquid-only clouds, and only liquid water path and liquid $r_{\mathrm{e}}$ are retrieved.

\section{Sources of error}

Sources of error in simulated radiances and fluxes include uncertainties in the liquid-water CRI, error in the DISORT calculations, error due to omitting the atmosphere above a certain altitude, and error due to sampling the optical depths on a finite wave-number grid. Errors in gaseous optical depths created using the LBLRTM are not considered because atmospheric profiles are meant to be typical examples only; furthermore, such uncertainties do not depend on the CRI and thus cancel out when flux and radiance differences are calculated. Other sources of error are discussed below.

\subsection{Uncertainties in the CRI}

Uncertainties in the calculated flux differences depend on uncertainties in the measured CRI. We use the Downing and Williams (1975) CRI as representative of the $\sim 300 \mathrm{~K}$ CRI. It differs from two other commonly used CRIs, those of Bertie and Lan (1996) and Hale and Querry (1973), by $1 \%$ for the real part of the CRI and $4 \%$ for the imaginary part, for 460 to $99 \mathrm{~cm}^{-1}$. As shown below, this variation is small compared to uncertainties in the temperature-dependent CRI.

The uncertainties in the CRI measurements of Zasetsky et al. (2005) and Wagner et al. (2005) are not well known. We use the comparison between the two sets between 800 and $930 \mathrm{~cm}^{-1}$ to get estimates of the uncertainty: differences are $\sim 8 \%, \sim 6 \%, \sim 3 \%$, and $\sim 5 \%$ for the $240 \mathrm{~K}, 253 \mathrm{~K}, 263 \mathrm{~K}$, and $273 \mathrm{~K}$ measurements, respectively.

Uncertainty in the CRI, $\sigma_{C}$, is propagated to uncertainty in the radiative flux calculations, $\sigma_{F}$, according to

$\sigma_{F}^{2}=\left[\frac{\delta F}{\delta C}\right]^{2} \sigma_{C}^{2}$,

where we calculate the change in flux with a change in CRI, $\delta F / \delta C$, numerically. For this, it is convenient to use as $\delta F$ the flux difference that we have already calculated, that is, the change in flux for a change in CRI from that of Downing and Williams (1975) at $300 \mathrm{~K}$ to the temperature-dependent CRI. Thus $\delta C$ is then $C_{300 \mathrm{~K}}-C_{T}$, where $C_{T}$ is, for example, $C_{240 \mathrm{~K}}$. For example, the uncertainty in the flux computed using the $240 \mathrm{~K} \mathrm{CRI}, F\left(C_{240 \mathrm{~K}}\right)$, is calculated as

$\sigma_{F\left(C_{240 \mathrm{~K}}\right)}^{2}=\left[\frac{F\left(C_{300 \mathrm{~K}}\right)-F\left(C_{240 \mathrm{~K}}\right)}{C_{300 \mathrm{~K}}-C_{240 \mathrm{~K}}}\right]^{2} \sigma_{C_{240 \mathrm{~K}}}^{2}$.

The $240 \mathrm{~K}$ CRI is on average $50 \%$ different than the $300 \mathrm{~K}$ CRI, so the denominator of Eq. (2) is $0.5 C_{240 \mathrm{~K}}$. As previously stated, the uncertainty in the $240 \mathrm{~K} \mathrm{CRI}$ is estimated to be $8 \%$, so $\sigma_{C}=0.08 C_{240 \mathrm{~K}}$. Plugging these into Eq. (2) gives an uncertainty of $0.2\left[F\left(C_{300 \mathrm{~K}}\right)-F\left(C_{240 \mathrm{~K}}\right)\right]$, or $20 \%$ of the flux difference.

The CRI measurements at $253 \mathrm{~K}, 263 \mathrm{~K}$, and $273 \mathrm{~K}$ differ from measurements at $300 \mathrm{~K}$ by $30 \%, 20 \%$, and $20 \%$. Thus, as a fraction of flux difference for each CRI temperature, uncertainty estimates made in this manner are $20 \%$ for $F\left(C_{253 \mathrm{~K}}\right), 20 \%$ for $F\left(C_{263 \mathrm{~K}}\right)$, and $30 \%$ for $F\left(C_{273 \mathrm{~K}}\right)$.

Uncertainties in cloud-property retrievals were calculated in a similar manner and are estimated to be about $20 \%$.

Note that the new temperature-dependent CRI is created from interpolating the real and imaginary parts separately. A rigorous treatment would be to recalculate the real part of the CRI from the imaginary part using the Kramers-Kronig transform. However, any errors in the real part of the CRI due to this method should be smaller than errors in the measurements of Zasetsky et al. (2005) and Wagner et al. (2005), from which they are derived.

\subsection{Error in DISORT calculations}

Error in DISORT calculations is due, in part, to the assumption that the Planck function is linear in optical depth across a layer. Errors due to this approximation can be minimized by making layers thin, so that the temperature difference across a layer is small. However, a sensitivity study showed that the accuracy of DISORT calculations is poor for layer optical depths less than $10^{-5}$. Thus layers need to be thick enough to have an adequately large optical depth, but thin enough to have a small temperature gradient. We carefully choose atmospheric layers such that the temperature differential across layers is $<5 \mathrm{~K}$ up to $10 \mathrm{~km}$ and $<10 \mathrm{~K}$ up to $60 \mathrm{~km}$.

Error estimates due to error in DISORT calculations range, for Arctic winter (AW) to tropical (TRP) model atmospheres, from 0.005 to $0.02 \mathrm{~W} \mathrm{~m}^{-2}$ for downwelling and 0.007 to $0.2 \mathrm{~W} \mathrm{~m}^{-2}$ for upwelling (more detail is given in the Supplement). Since these errors do not depend on the CRI, they should cancel out to a large degree when flux and radiance difference are calculated.

\subsection{Error due to choice of TOA}

Even with careful choice of layering, at some wave numbers, optical depths below $10^{-5}$ occur at altitudes as low as $10 \mathrm{~km}$, while at other wave numbers (near strong line centers), optical depths can still be large enough that the atmosphere above $30 \mathrm{~km}$ needs to be included for good accuracy. Thus, for each DISORT run (each spectral data point), the atmospheric profile was topped at the highest layer with an optical depth greater than $10^{-5}$. This resulted in a wave-numberdependent model TOA ranging from 8.5 to $60 \mathrm{~km}$. Errors in fluxes and radiances due to excluding such small optical depths through truncating the atmosphere below $60 \mathrm{~km}$ are small; the range of resulting errors, for AW to TRP, is estimated to be 0.002 to $0.0007 \mathrm{~W} \mathrm{~m}^{-2}$ for downwelling fluxes 

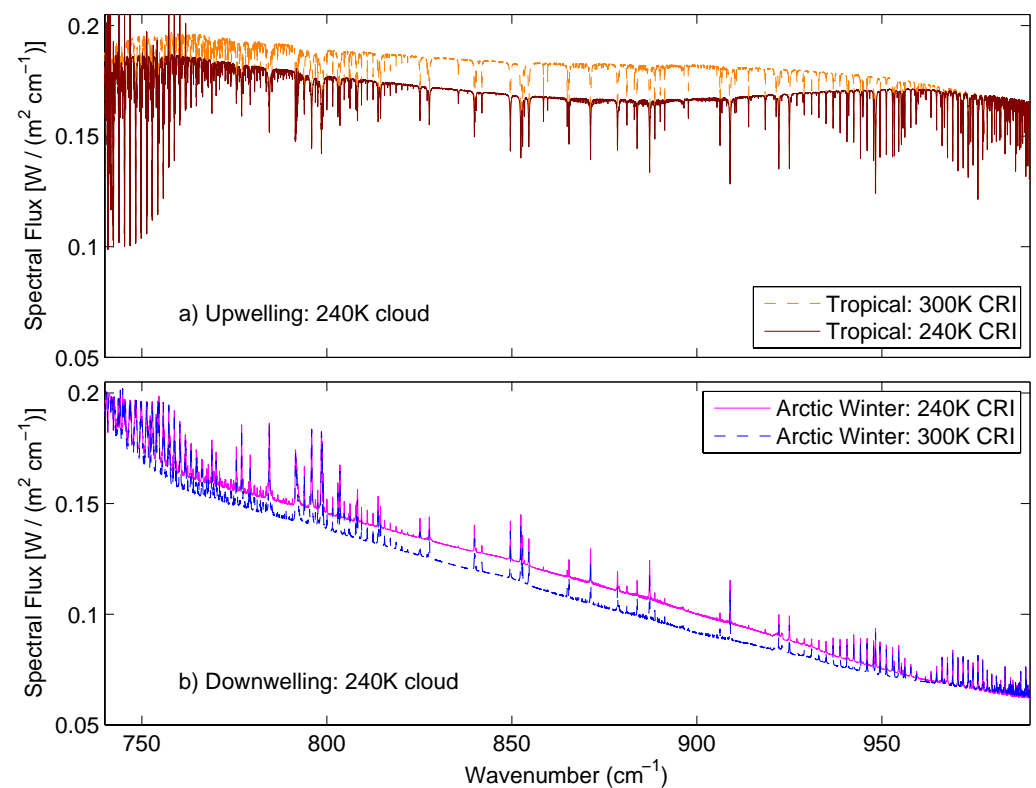

Fig. 3. Spectral flux for a cloudy atmosphere containing a single-layer liquid cloud at $240 \mathrm{~K}$, simulated using a conventional complex refractive index (CRI) based on measurements made at $300 \mathrm{~K}$ and using a new CRI for $240 \mathrm{~K}$. The droplet effective radius was $5 \mu \mathrm{m}$, and the cloud liquid water path was $8 \mathrm{~g} \mathrm{~m}^{-2}$. (a) Upwelling spectral flux for a tropical atmosphere and (b) downwelling spectral flux for an Arctic winter atmosphere.

and 0.0002 to $0.001 \mathrm{~W} \mathrm{~m}^{-2}$ for upwelling fluxes. Errors in radiances used for cloud-property retrievals are similarly small.

\subsection{Error due to wave-number sampling}

Error due to sampling the optical depths on a finite wavenumber grid is minimized by selecting a fine wave-number spacing $\left(0.01 \mathrm{~cm}^{-1}\right)$ so that most strong gaseous lines are well-sampled for integrating over wave number. The LBLRTM calculates optical depths at perfect (monochromatic) resolution and outputs them on a spacing that becomes finer going up in the atmosphere (e.g., down to $2 \times 10^{-4} \mathrm{~cm}^{-1}$ at $60 \mathrm{~km}$ ). Because DISORT is run for each spectral point, running DISORT at the finest wave-number sampling would take prohibitively long. The wave-number spacing chosen represents that of the lowest layer. The range of resulting errors, for AW to TRP, is estimated to be 0.0002 to $0.0003 \mathrm{~W} \mathrm{~m}^{-2}$ for downwelling and 0.003 to $0.006 \mathrm{~W} \mathrm{~m}^{-2}$ for upwelling fluxes. Errors are negligible in the radiances between strong gaseous emission lines used to retrieve cloud properties.

\subsection{Combined uncertainties}

The combined uncertainties in the flux differences due to the choice of TOA and wave-number sampling of the simulated fluxes are estimated to range, for AW to TRP, from 0.002 to $0.0007 \mathrm{~W} \mathrm{~m}^{-2}$ for downwelling and from 0.003 to $0.006 \mathrm{~W} \mathrm{~m}^{-2}$ for upwelling. For flux differences greater than $0.2 \mathrm{~W} \mathrm{~m}^{-2}$, uncertainties in the measured CRI dominate over these sources and the uncertainty is $20 \%$. For cloud-property retrievals, uncertainties in the measured CRI dominate and the combined uncertainties are $20 \%$ for cloud effective radius and water path.

\section{Results and discussion}

\subsection{Spectral fluxes}

For a cloud at $240 \mathrm{~K}$, simulated upwelling spectral fluxes are found to be biased high for the TIA (300 K CRI), compared to fluxes for the $240 \mathrm{~K} \mathrm{CRI}$, as shown in Fig. 3a for a tropical atmosphere. Simulated downwelling fluxes are biased low for the TIA (Fig. 3b; Arctic winter). Similar but smaller effects occur in the dirty window for both upwelling and downwelling. Similar but smaller effects also occur for other cloud temperatures and atmospheric profiles (as shown in the Supplement). Figure 2 (discussed in Sect. 3.2) suggests that such biases are equivalent to underestimating cloudiness. Use of the TIA therefore underestimates the local greenhouse effect of supercooled clouds.

\subsection{Upwelling flux differences}

Figure $4 \mathrm{a}$ and $\mathrm{b}$ show the upwelling flux differences (flux (300 K CRI) - flux (240 K CRI)) as a function of LWP. The upwelling flux differences are positive and increase from the Arctic winter to the tropics, in tandem with the cloud radiative effect (as was shown in Fig. 2), and decrease as $r_{\mathrm{e}}$ 

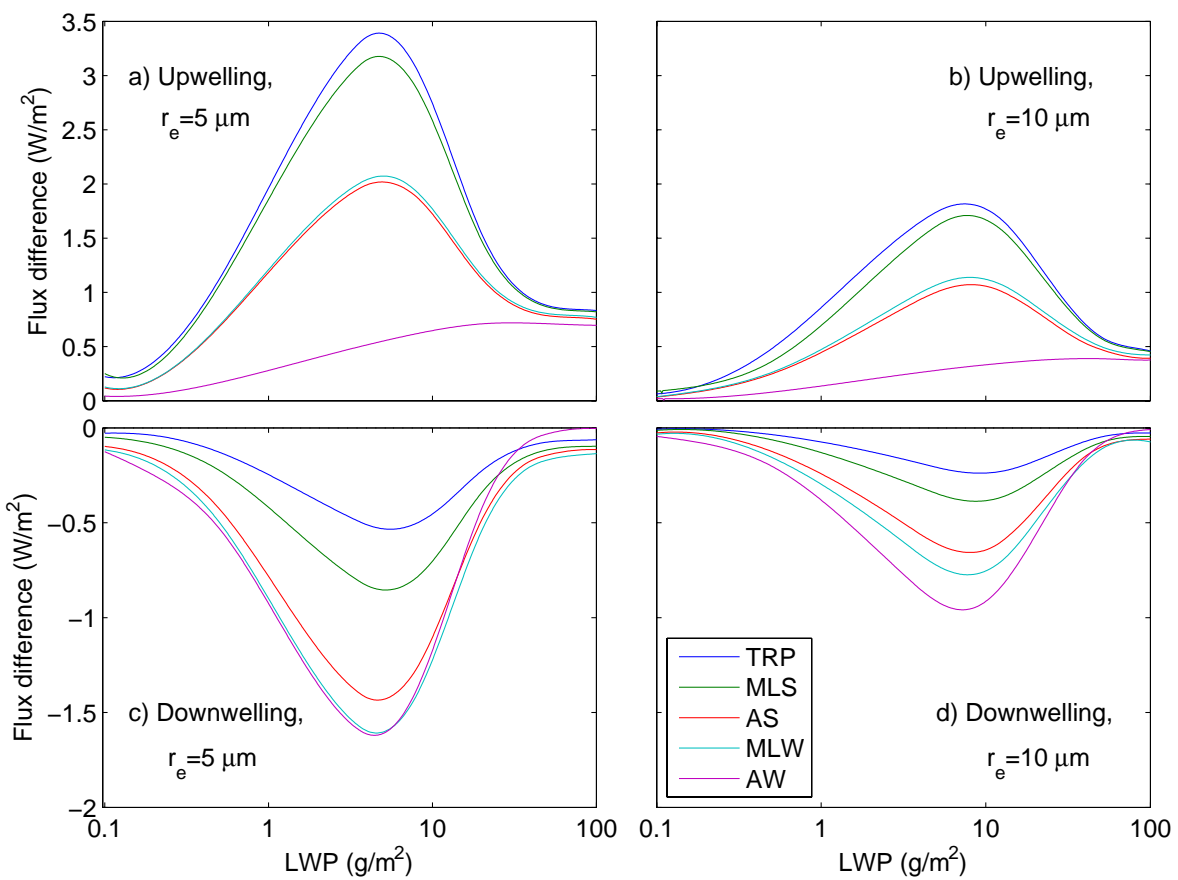

Fig. 4. Difference between flux simulated using the $300 \mathrm{~K}$ complex retractive index (CRI) and using a $240 \mathrm{~K}$ CRI (see text for explanation) as a function of cloud liquid water path (LWP) for single-layer liquid clouds with effective radii of 5 and $10 \mu \mathrm{m}$ in a variety of model atmospheres (Arctic winter: AW, midlatitude winter: MLW, Arctic summer: AS, midlatitude summer: MLS, and tropical: TRP), for upwelling flux at the top of atmosphere (a and $\mathbf{b}$ ) and downwelling flux at the surface (c and $\mathbf{d}$ ).

increases. For all atmospheric profiles except Arctic winter, the flux differences increase with LWP up to about $5 \mathrm{~g} \mathrm{~m}^{-2}$ for an $r_{\mathrm{e}}$ of $5 \mu \mathrm{m}$, after which they begin to decrease, until finally trending toward a constant value. For Arctic winter, the LWP does not peak, but rather increases slowly with LWP up to a similar constant value $\left(\sim 0.7 \mathrm{~W} \mathrm{~m}^{-2}\right)$.

For all atmospheric profiles except Arctic winter, LWPs at the peaks correspond to infrared optical depths fairly close to one. At an optical depth near one, the cloud is optically thick enough that absorption and emission are strong, but thin enough that thermal emission is still quite sensitive to the refractive index. This is why the largest flux differences due to differences in the CRI occur at these LWPs. As a cloud continues to get optically thicker (e.g., LWP $>90 \mathrm{~g} \mathrm{~m}^{-2}$ in Fig. $4 \mathrm{a}$ and $\mathrm{b}$ ), it becomes more like a blackbody, thermal emission becomes less sensitive to the CRI, and thus flux differences decrease.

For the Arctic winter, there is no peak in flux difference as a function of LWP because the cloud and surface are at similar temperatures, so thermal emission from the cloud resembles thermal emission from the surface. The gradual rise in flux differences with LWP can be explained by multiple scattering, which is expected to increase with cloud thickness until reaching a maximum for an optically thick cloud.

Multiple scattering can also explain why flux differences trend toward a constant value rather than falling to zero for high LWP for the other atmospheric profiles. The trending to- ward a constant value has important consequences for cloud modeling, since it implies that use of the TIA will cause biases in cloudy-sky flux for supercooled liquid clouds of any optical thickness.

The largest upwelling flux differences are for a $240 \mathrm{~K}$ tropical liquid cloud: $3.4 \pm 0.7 \mathrm{~W} \mathrm{~m}^{-2}\left(r_{\mathrm{e}}=5 \mu \mathrm{m}\right)$ and $1.8 \pm$ $0.4 \mathrm{~W} \mathrm{~m}^{-2}\left(r_{\mathrm{e}}=10 \mu \mathrm{m}\right)$.

\subsection{Downwelling flux differences}

Figure $4 \mathrm{c}$ and $\mathrm{d}$ show downwelling flux differences. Trends are similar to those for upwelling, but the flux differences are negative, also consistent with underestimating the local greenhouse warming due to the cloud. For all atmospheric profiles, downwelling flux differences have minima at LWPs similar to those for which upwelling flux differences peaked. At large LWP, flux differences trend toward a small, constant value for all atmospheric profiles but Arctic winter, which trends toward zero.

For downwelling flux differences, the minima occur at infrared optical depths near one because downwelling flux differences are largest when the cloud is optically thick enough that emission is strong, but thin enough that thermal emission is sensitive to the CRI.

As for upwelling flux differences, scattering can explain the dependence of downwelling flux differences on the CRI 
for optically thick clouds. However, downwelling flux differences at large LWPs are quite small.

The largest-magnitude downwelling flux differences are for the Arctic winter $240 \mathrm{~K}$ liquid cloud: $-1.6 \pm 0.3 \mathrm{~W} \mathrm{~m}^{-2}$ $\left(r_{\mathrm{e}}=5 \mu \mathrm{m}\right)$ and $-0.95 \pm 0.2 \mathrm{Wm}^{-2}\left(r_{\mathrm{e}}=10 \mu \mathrm{m}\right)$. These flux differences, and the flux differences of 3.4 and $1.8 \mathrm{~W} \mathrm{~m}^{-2}$ for tropical upwelling flux, are significant when compared to the total net anthropogenic global radiative forcing at the tropopause of $1.6(-0.6,+0.24) \mathrm{W} \mathrm{m}^{-2}$ (Forster et al., 2007).

\subsection{Cloud-property retrievals}

The use of the TIA also induces errors in retrievals of cloud properties that rely on infrared radiative transfer. Because the CRI of supercooled liquid water is more similar to ice than that for the TIA, cloud phase retrievals using the TIA retrieve an ice fraction that is biased high. For the downwelling radiance simulation for the Arctic winter (240 K liquid-only cloud), if the simulation is created using the temperaturedependent CRI, but the TIA is used for the retrieval, an ice fraction of $\sim 5 \%$ is retrieved (see Fig. 5; the water path, $8 \mathrm{~g} \mathrm{~m}^{-2}$, and liquid $r_{\mathrm{e}}, 10 \mu \mathrm{m}$, are assumed to be known; the retrieved ice $r_{\mathrm{e}}=4 \mu \mathrm{m}$ ). Thus, retrievals using the TIA may detect ice even if none is present. For a wider range of simulations (liquid $r_{\mathrm{e}}$ of 5 to $15 \mu \mathrm{m}$ and LWP of 4 to $11 \mathrm{~g} \mathrm{~m}^{-2}$ ), use of the TIA leads to retrievals of ice fractions of $0 \%$ to $12 \%$, with ice $r_{\mathrm{e}}$ of 1 to $10 \mu \mathrm{m}$. (These ice $r_{\mathrm{e}}$ values are small compared to estimates of $\sim 15 \mu \mathrm{m}$ at $240 \mathrm{~K}$ for midlatitude clouds; Garrett et al., 2003.)

For retrievals that assume that the cloud is known to be liquid only, and instead retrieve liquid $r_{\mathrm{e}}$ and LWP, for the same cloud types, errors in retrieved $r_{\mathrm{e}}$ will be -3.2 to $0.5 \mu \mathrm{m}$ and errors in LWP will be -2.3 to $0.6 \mathrm{~g} \mathrm{~m}^{-2}$.

\section{Conclusions}

Supercooled clouds are important for the climate system globally. The infrared properties of such clouds depend on their complex refractive indices. Although recent measurements have been made of liquid cloud CRI down to temperatures as low as $240 \mathrm{~K}$ (Zasetsky et al., 2005; Wagner et al., 2005), calculations of flux from supercooled liquid clouds and retrievals of supercooled cloud properties that make use of infrared radiance measurements typically rely on a CRI based on measurements at $\sim 300 \mathrm{~K}$. We present biases in fluxes and cloud-property retrievals for supercooled liquid clouds when the CRI is assumed to be temperature independent.

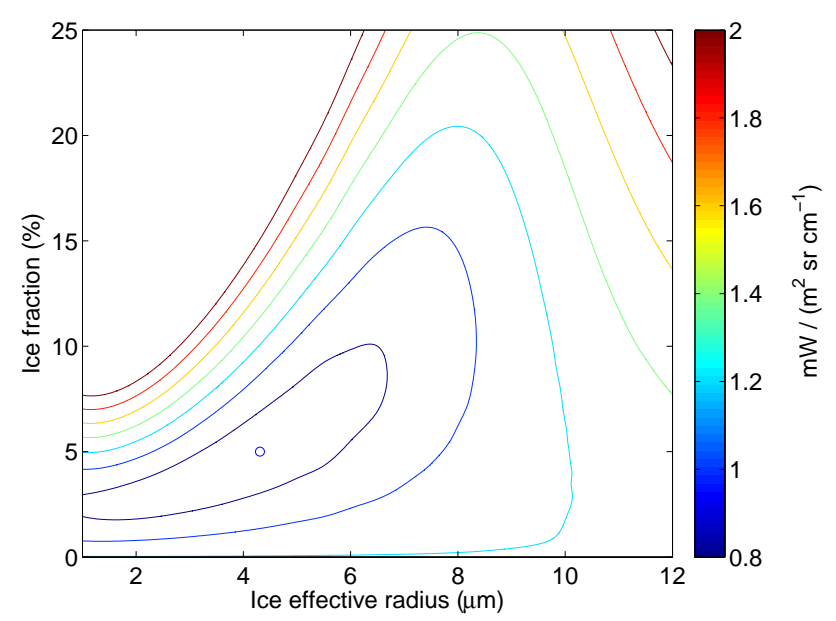

Fig. 5. Contours of the root mean square (rms) difference between simulated downwelling radiances from a look-up table and a model "measured" radiance, at selected frequencies (see text). Both measured and simulated radiances are for a $240 \mathrm{~K}$ cloud with a liquid water path of $8 \mathrm{~g} \mathrm{~m}^{-2}$ and liquid-droplet effective radius of $10 \mu^{-2}$. The measured radiance is for an ice fraction of zero and thus has no dependence on ice effective radius; it was created using liquid water refractive indices measured at $240 \mathrm{~K}$. Simulated radiances are for the ice effective radii and ice fractions given along the $x$ and $y$ axes and were created using liquid water refractive indices measured at $300 \mathrm{~K}$. The circle marks the minimum rms difference.

Flux differences were calculated for the spectral regions from 460 to $640 \mathrm{~cm}^{-1}$ and 760 to $990 \mathrm{~cm}^{-1}$, where cloud signal is strong and where the temperature dependence of the CRI is known. Cloud properties were retrieved in microwindows between strong gaseous emission lines in the same spectral region.

We find that flux simulations of $240 \mathrm{~K}$ supercooled singlelayer liquid clouds ( $r_{\mathrm{e}}$ of 5 to $10 \mu \mathrm{m}$ ) that use a CRI based on measurements made at $300 \mathrm{~K}$ lead to underestimation of the local cloud greenhouse effect. Compared to fluxes using a new CRI for $240 \mathrm{~K}$, downwelling infrared fluxes using the TIA are too low (by up to $1.7 \mathrm{~W} \mathrm{~m}^{-2}$ ), with the largest effect in cold regions, and upwelling fluxes are too high (by up to $3.4 \mathrm{~W} \mathrm{~m}^{-2}$ ), with the largest effect in warm regions. Furthermore, TIA-based retrievals of cloud properties introduce spurious ice, or underestimate cloud thickness and droplet size, depending on algorithm constraints.

Additional laboratory measurements are needed to confirm recent measurements of the CRI of supercooled water (Zasetsky et al., 2005; Wagner et al., 2005) and reduce uncertainties in the measured CRI throughout the infrared. Meanwhile, climate models and cloud retrievals should use the new, temperature-dependent CRI for greatest accuracy.

\section{Supplementary material related to this article is available online at http://www.atmos-chem-phys.net/13/ 11925/2013/acp-13-11925-2013-supplement.pdf.}


Acknowledgements. We are grateful to A. F. Khalizov, R. Lynch, and T. C. Grenfell for helpful discussions. Support for this research came from the National Aeronautics and Space Administration (NASA) Research Opportunities in Space and Earth Sciences program (contract NNX08AF79G) and from the National Science Foundation (NSF) Idaho Experimental Program to Stimulate Competitive Research (EPSCoR). S. Neshyba acknowledges support from the University of Puget Sound and the National Science Foundation under grant CHE - 1306366.

Edited by: A. Geer

\section{References}

Bertie, J. E. and Lan, Z.: Infrared intensities of liquids XX: The intensity of the $\mathrm{OH}$ stretching band of liquid water revisited, and the best current values of the optical constants of $\mathrm{H}_{2} \mathrm{O}(1)$ at $25^{\circ} \mathrm{C}$ between 15,000 and $1 \mathrm{~cm}^{-1}$, Appl. Spec., 50, 1047-1057, 1996.

Cesana, G., Kay, J. E., Chepfer, H., English, J. M., and de Boer, G.: Ubiquitous low-level liquid-containing Arctic clouds: new observations and climate model constraints from CALIPSO-GOCCP, Geophys. Res. Lett., 39, L20804, doi:10.1029/2012GL053385, 2012.

Clough, S. A., Shephard, M. W., Mlawer, E. J., Delamere, J. S., Iacono, M. J., Cady-Pereira, K., Boukabara, S., and Brown, P. D.: Atmospheric radiative transfer modeling: a summary of the AER codes, J. Quant. Spectrosc. Radiat. Transf., 91, 233-244, 2005.

Downing, H. D. and Williams, D.: Optical constants of water in the Infrared, J. Geophys. Res., 80, 1656-1661, 1975.

Forster, P., Ramaswamy, V., Artaxo, P., Berntsen, T., Betts, R., Fahey, D. W., Haywood, J., Lean, J., Lowe, D. C., Myhre, G., Nganga, J., Prinn, R., Raga, G., Schulz, M., and Van Dorland, R.: Changes in Atmospheric Consitutents and in Radiative Forcing, in: Climate Change 2007: The Physical Science Basis, Contribution of Working Group I to the Fourth Assessment Report of the Intergovernmental Panel on Climate Change, edited by: Solomon, S., Qin, D., Manning, M., Chen, Z., Marquis, M., Averyt, K. B., Tignor, M., and Miller, H. L., Cambridge University Press, Cambridge, UK and New York, NY, USA, 106 pp., 2001.

Garrett, T. J., Gerber, H., Baumgardner, D. G., Twohy, C. H., and Weinstock, E. M.: Small, highly reflective ice crystals in low-latitude cirrus, Geophys. Res. Lett., 30, 2132, doi:10.1029/2003GL018153, 2003.

Hale, G. M. and Querry, M. R.: Optical constants of water in the 200-nm to 200- $\mu$ m region, Appl. Optics, 12, 555-563, 1973.

Hogan, R. J., Illingworth, A. J., O'Connor, E. J., and Baptista, J. P. V. P.: Characterisitics of mixed-phase clouds, II. A climatology from ground-based lidar, Q. J. Roy. Meteorol. Soc., 129, 2117-2134, 2003.

Hu, Y., Rodier, S., Xu, K., Sun, W., Huang, J., Lin, B., Zhai, P., and Josset, D.: Occurrence, liquid water content, and fraction of supercooled water clouds from combined CALIOP/IIR/MODIS measurements, J. Geophys. Res., 115, D00H34, doi:10.1029/2009JD012384, 2010.

Intrieri, J. M., Shupe, M. D., Uttal, T., and McCarty, B. J.: An annual cycle of Arctic cloud characteristics observed by radar and lidar at SHEBA, J. Geophys. Res., 107, 8030, doi:10.1029/2000JC000423, 2002.
Koop, T., Luo, B., Tsias, A., and Peter, T.: Water activity as the determinant for homogenous ice nucleation in aqueous solutions, Nature, 406, 611-614, 2000.

Randall, D. A., Wood, R. A., Bony, S., Colman, R., Fichefet, T., Fyfe, J., Kattsov, V. Pitman, A., Shukla, J., Srinivasan, J., Stouffer, R. J., Sumi, A., and Taylor, K. E.: Climate Models and Their Evaluation, in: Climate Change 2007: The Physical Science Basis. Contribution of Working Group I to the Fourth Assessment Report of the Intergovernmental Panel on Climate Change, edited by: Solomon, S., Qin, D., Manning, M., Chen, Z., Marquis, M., Averyt, K. B., Tignor, M., and Miller, H. L., Cambridge University Press, Cambridge, United Kingdom and New York, NY, USA, 2007.

Rodgers, C. D.: Inverse Methods for Atmospheric Sounding: Theory and Practice, World Scientific Publishing Co. Pte. Ltd, Singapore, 256 pp., 2000.

Rosenfeld, D. and Woodley, W. L.: Deep convective clouds with sustained supercooled liquid water down to $-37.5^{\circ} \mathrm{C}$, Nature, 405, 440-442, 2000.

Stamnes, K., Tsay, S.-C., Wiscomb, W., and Jayaweera, K.: Numerically stable algorithm for discrete-ordinate-method radiative transfer in multiple scattering and emitting layered media, Appl. Optics, 27, 2502-2509, 1988.

Toon, O. B., Tolbert, M. A., Koehler, B. G., Middlebrook, A. M., and Jordan, J.: The infrared optical constants of $\mathrm{H}_{2} \mathrm{O}$-ice, amorphous nitric acid solutions, and nitric acid hydrates, J. Geophys. Res., 99, 25631-25654, 1994.

Verlinde, J., Harrington, J. Y., McFarqhar, G. M., Yannuzzi, V. T., Avramov, A., Greenberg, S., Johnson, N., Zhang, G., Poellot, M. R., Mather, J. H., Turner, D. D., Eloranta, E. W., Zak, B. D., Prenni, A. J., Daniel, J. S., Kok, G. L., Tobin, D. C., Holz, R., Sassen, K., Spangenberg, D., Minnis, P., Tooman, T. P., Ivey, M. D., Richardson, S. J., Bahrmann, C. P., Shupe, M., Demott, P. J., Heymsfield, A. J., and Schofield, R.: The mixed-phase Arctic cloud experiment, B. Am. Meteorol. Soc., 88, 205-221, doi:10.1175/BAMS-88-2-205, 2007.

Wagner, R., Benz, S., Möhler, O., Saathoff, H., Schnaiter, M., and Schurath, U.: Mid-infrared extinction spectra and optical constants of supercooled water droplets, J. Phys. Chem. A, 109, 7099-7112, 2005.

Warren, S. G. and Brandt, R. E.: Optical constants of ice from the ultraviolet to the microwave: a revised compilation, J. Geophys. Res., 113, D14220, doi:10.1029/2007JD009744, 2008.

Zasetsky, A. Y., Khalizov, A. F., and Sloan, J. J.: Local order and dynamics in supercooled water: a study by IR spectroscopy and molecular dynamic simulations, J. Chem. Phys., 121, 69416947, 2004.

Zasetsky, A. Y., Khalizov, A. F., Earle, M. E., and Sloan, J. J.: Frequency dependent complex refractive indices of supercooled liquid water and ice determined from aerosol extinction spectra, J. Phys. Chem. A., 109, 2760-2764, 2005.

Zhang, D., Wang, Z., and Liu, D.: A global view of midlevel liquidlayer topped stratiform cloud distribution and phase partition from CALIPSO and CloudSat measurements, J. Geophys. Res., 115, D00H13, doi:10.1029/2009JD012143, 2010. 